\title{
Optimization of Supercritical Carbon Dioxide and Co-solvent Ethanol Extraction of Wasted Peanut Skin Using Response Surface Methodology
}

\author{
Nicky Rahmana Putra ${ }^{1,2}$, Ahmad Hazim Abdul Aziz ${ }^{1}$, Lee Nian Yian ${ }^{1}$, Wan Diyana Ramli ${ }^{1}$, and Mohd Azizi Che Yunus ${ }^{*}$ \\ ${ }^{1}$ Centre of Lipid Engineering and Apllied Research (CLEAR), Ibnu Sina Institute for Scientific and Industrial Research, Universiti \\ Teknologi Malaysia, 81310, UTM Johor Bahru, Malaysia \\ ${ }^{2}$ Faculty of Chemical and Energy Engineering, Universiti Teknologi Malayia, 81310, Johor Bahru,Malaysia
}

\begin{abstract}
Peanut skin is a waste of peanut industries especially peanut butter industries. Peanut skin contain high antioxidant and high nutritional values. The objective of this study was to optimize the effect of parameters to obtain high extract yield and high antioxidant activity by using supercritical carbon dioxide and co-solvent ethanol. A Box-Behnken design (BBD) was used to optimize the extraction process at the condition temperature $\left(40,55\right.$ and $\left.70{ }^{\circ} \mathrm{C}\right)$, rate of co-solvent ethanol $(2.5,5$, and $7.5 \%$ Vethanol/Vtotal), and extraction pressure $(10,20$ and 30 $\mathrm{MPa}$ ). The extraction time was 3 hours. The optimum condition to obtain yield of extraction and antioxidant activity $22.05 \mathrm{MPa}, 62.76{ }^{\circ} \mathrm{C}$ and $6.03 \%\left(\mathrm{~V}_{\text {ethanol }} / \mathrm{V}_{\text {solvent }}\right)$ with $15.404 \%$ yield extract and $94.040 \%$ antioxidant activity.
\end{abstract}

\section{Introduction}

Peanut is an agricultural product that has been used for many dishes in the asean country such as Indonesia, Malaysia and Philippines. In food industries, peanut skin is always removed from peanut due to taste of product. Peanut skin decreases the quality of product because peanut skin has astringent taste. Astringent taste indicates that peanut skin contains high antioxidant inside of its skin. Previous researcher has already found that peanut skin contains procyianidin, catechin, epicatechin, and anthocyanidin [1,2]. Most of this antioxidant of peanut skin extract reduced risk of cardiovascular diseases and cancers, anti-diabetic, antiinflammatory [3].

Supercritical carbon dioxide is a green and safe technology to extract oil, bioactive compounds and antioxidant. Furthermore, supercritical carbon dioxide does not have residues after extraction process because carbon dioxide will be naturally separated from the extract. Moreover, supercritical carbon dioxide extraction has many advantages in food process extraction because unexpansive as solvent, and also has small critical temperature and pressure (304 $\mathrm{K}$ and 71 Bar). Although, supercritical carbon dioxide has many advantages, the built up the extraction apparatus is expensive but the extract of extraction has high quantity of bioactive compound and antioxidant activity compared with conventional extraction such as soxhlet extraction.
Many researchers has successfully used supercritical carbon dioxide extraction to extract bioactive compounds from herbs and plants effectively. Recently, pipper batle leaves, Pithecellobium Jiringan (Jack) prain seeds, palm oil, and rubber seeds oil are successfully extracted by supercritical carbon dioxide extraction $[4,5,6,7,8]$. Moreover, high selectivity and diffusivity to certain compound and condition in the solute are the significant advantages of using supercritical carbon dioxide. furthermore, the another advantages of supercritical carbon dioxide extraction is the solubility of solvent can be manipulated by pressure, rate of cosolvent and temperature [9].

Ethanol as co-solvent in the extraction process is needed for this extraction process to encourage the polarity of solvent. Therefore, with addition co-solvent ethanol in the supercritical carbon dioxide extraction can extract polar and non-polar compounds inside of the solute. Moreover, Ethanol is safer than other commonly co-solvent such as methanol, propanol and butanol because in the market, ethanol is sold with food grade quality.

To optimize and determine influences of variables and fitted the experimental data on the supercritical carbon dioxide extraction has successfully used by response surface methodology (RSM). Commonly, pressure, temperature and rate of co-solvent are the variables of extraction process. From previous studies shows that extraction of red-fleshed pitaya, piper battle linn leaveas[10], tomato skin[11], Passiflora seed oil,

Corresponding author: azizi@cheme.utm.my 
and palm oil [12] have successfully optimized by response surface methodology.

The aim of this work was to optimize effect parameters to obtain high extract yield and antioxidant activity.

\section{Materials and Methods}

\subsection{Materials}

Peanut skin was obtained from G-Tachfood Industries SDN-BHD. For the pre-treatment process, peanut skin was dried in oven at $60^{\circ} \mathrm{C}$ for 4 hours and blended into powder with average size of particle $425 \mu \mathrm{m}$ and placed in the freezer until used $\left(-20{ }^{\circ} \mathrm{C}\right)$. Liquid carbon dioxide (99\% purity) was purchased from Kras Instrument, Johor Bahru, Malaysia. Food grade of ethanol (99.86\%) was obtained from Permula Sdn Bhd, Johor Bahru Malaysia.

\subsection{Extraction Process}

\subsubsection{Supercritical Carbon Dioxide and Co-solvent Ethanol Extraction}

A set of supercritical carbon dioxide and co-solvent ethanol extraction apparatus was used for this experiment. The extraction time was 3 hours with every 30 minutes of extraction process, extracts was collected and recorded. The flowrate of carbon dioxide is maintained $3 \mathrm{~mL} / \mathrm{min}$ by HPLC pump (Lab Alliance, Series II Pump) from the $\mathrm{CO}_{2}$ tank into the system continuously, and also co-solvent ethanol $98.86 \%$ was pumped continuously when the desired temperature was achieved. Temperature of chiller and back pressure regulator (Jasco BP 2080 Plus Automated BPR) was set at $6^{\circ} \mathrm{C}$ and $50^{\circ} \mathrm{C}$. Next, $5 \pm 0.005 \mathrm{~g}$ of peanut skin was placed into extraction vessel.

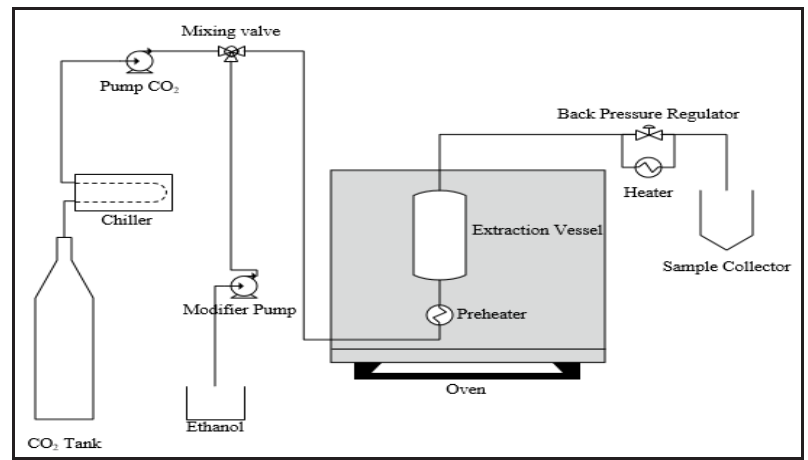

Fig.1. schemes of supercritical carbon dioxide and cosolvent ethanol extraction apparatus

\subsubsection{Soxhlet Extraction}

Soxhlet extraction is conventional extraction process. Soxhlet extraction gives high extract yield due to exhausting process and small amount of solvents in the extraction process. In this study, a comparison antioxidant activity between supercritical carbon dioxide extraction and soxhlet extraction were revealed. The solvents used was ethanol, n-hexane and water. The particle size was $425 \mu$ and extraction time was 6 hours.

\subsection{Determination of Antioxidant Activity}

The determination of antioxidant activity by 2,2diphenyl-1-picryl-hydrazyl-hydrate (DPPH) of peanut skin extract was evaluated as described by previous study[13]. First of all, the peanut skin extract $0.5 \mu \mathrm{gr} / \mathrm{L}$ was mixed with a $0.165 \mathrm{mM}$ ethanoic (DPPH). Furthermore, $30 \mathrm{~min}$ incubation at room temperature. Spectrophotometer UV-Vis (Webler) was used to obtain the absorbance values were measured at $516 \mathrm{~nm}$ and converted into percentage of antioxidant activity ( $\%$ AA). The measurement of antioxidant activity is:

$$
(\% \mathrm{AA})=\left(\mathrm{A}_{\mathrm{a}}-\mathrm{A}_{\mathrm{b}}\right) / \mathrm{A}_{\mathrm{a}} \times 100 \%
$$

Where $\% \mathrm{AA}$ is percentage of antioxidant activity, $\mathrm{A}_{\mathrm{a}}$ is absorbance of DPPH solution and $A_{b}$ is absorbance of mixture between DPPH solution and extract solution.

\subsection{Experimental Design}

Three parameters of this study are pressure $\left(\mathrm{X}_{1}\right)$, temperature $\left(\mathrm{X}_{2}\right)$ and rate of co-solvent ethanol $\left(\mathrm{X}_{3}\right)$ in order to obtain optimum yield extract of peanut skin, $\mathrm{Y}_{1}$ and percentage of antioxidant activity, $\mathrm{Y}_{2}$. Box Behnken Design was used for experimental design.

Table 1. Factors and levels for the experimental design

\begin{tabular}{|c|c|c|c|}
\hline Factors & $\begin{array}{c}\text { Low } \\
(-1)\end{array}$ & $\begin{array}{c}\text { Medium } \\
(0)\end{array}$ & $\begin{array}{c}\text { High } \\
(+1)\end{array}$ \\
\hline Pressure, $\left(\mathrm{X}_{1}, \mathrm{MPa}\right)$ & 10 & 20 & 30 \\
\hline Temperature, $\left(\mathrm{X}_{2},{ }^{\circ} \mathrm{C}\right)$ & 40 & 55 & 70 \\
\hline $\begin{array}{c}\text { Rate of Co-solvent } \\
\left(\mathrm{X}_{3}, \%\right)\end{array}$ & 2.5 & 5 & 7.5 \\
\hline
\end{tabular}

In this study, quadratic model was used to fit the experimental data as follows:

$Y=B_{0}+\sum_{i=1}^{k} B_{i} X_{i}+\sum_{i=1}^{k} B_{i} X_{i}^{2}+\sum_{i} \sum_{j} B_{i j} X_{i} X_{j}$

$\mathrm{Y}$ is the predicted response, $\mathrm{B}_{0}$ is a constant, $\mathrm{B}_{\mathrm{i}}, \mathrm{B}_{\mathrm{ii}}, \mathrm{B}_{\mathrm{ij}}$ are the interaction of effect, $X_{i}$ and $X_{j}$ are coded value of factor. Furthermore, the response surfaces of the variables inside the experimental domain were analyzed by analysis of variance (ANOVA).

\section{Result and discussion}

\subsection{Experimental Result}

To optimize the extraction process, the effect of pressure, temperature and rate of co-solvent were the three main variables in order to obtain high extract yield and high antioxidant activity on peanut skin extract. The three variables was investigate by using second order 
polynomial statistical model. Preliminary studies was needed to determine fixed variables of the optimization. The quadratic effect of the treatments variables, their interactions and coefficients on the response variables were obtained by analysis of variance (ANOVA). Experimental design was made by using box bhenken design shown in table 2 .

Table 2. The experimental design for the $\mathrm{SC}-\mathrm{CO}_{2}$

\begin{tabular}{|c|c|c|c|c|c|}
\hline $\begin{array}{c}\mathrm{Ru} \\
\mathrm{n}\end{array}$ & $\begin{array}{c}\text { Pressur } \\
\mathrm{e}, \mathrm{X}_{1} \\
(\mathrm{MPa})\end{array}$ & $\begin{array}{c}\text { Temp } \\
\text { eratur } \\
\mathrm{e}, \mathrm{X}_{2} \\
\left({ }^{\circ} \mathrm{C}\right)\end{array}$ & $\begin{array}{c}\text { Rate of } \\
\text { Co- } \\
\text { solvent } \\
\mathrm{X}_{3} \\
(\%)\end{array}$ & $\begin{array}{c}\text { Yield } \\
(\%)\end{array}$ & AA \\
$(\%)$
\end{tabular}

From the table 2 shows that the highest amount of yield extract as experimental data was $15.4048 \%$ with condition $30 \mathrm{MPa}, 70{ }^{\circ} \mathrm{C}$ and $5 \%$ rate of co-solvent. Furthermore, The highest antioxidant activity was obtain at condition $20 \mathrm{MPa}, 55{ }^{\circ} \mathrm{C}$ and $5 \%$ rate of co-solvent ethanol was $94.04 \%$.

\subsection{Statistical Data Analysis}

The analysis of variance (ANOVA) is presented in Table 3 for extract yield and antioxidant activity. Based on the analysis, second order polynomial equation was chosen and successful to optimize the extract yield and antioxidant activity of peanut. The analysis showed that both models were statistically significant $($ sig. $<0.05)$ at
$95 \%$ confidence. The coefficients of quadratic model are shown in Tables 5 and 6.

Table 3. ANOVA table of supercritical carbon dioxide and cosolvent ethanol extration

\begin{tabular}{|l|l|l|l|l|l|}
\hline Source & $\begin{array}{c}\text { Sum of } \\
\text { square }\end{array}$ & df & $\begin{array}{c}\text { Mean } \\
\text { Square }\end{array}$ & F & $\begin{array}{c}\text { p- } \\
\text { value }\end{array}$ \\
\hline Extract Yield \\
\hline Regression & 98.17 & 9 & 10.91 & 4.64 & $\begin{array}{l}0.027 \\
8\end{array}$ \\
\hline Residual & 16.47 & 7 & 2.35 & & \\
\hline Total & 114.65 & 16 & & & \\
\hline Antioxidant Activity \\
\hline Regression & 765.95 & 9 & 85.11 & 5.17 & $\begin{array}{l}0.020 \\
7\end{array}$ \\
\hline Residual & 115.21 & 7 & 16.46 & & \\
\hline Total & 881.16 & 16 & & & \\
\hline
\end{tabular}

Table 4. Coefficient of polynomial quadratic model of extract yield

\begin{tabular}{|c|l|l|l|}
\hline $\begin{array}{c}\text { Extract yield } \\
(\%)\end{array}$ & $\begin{array}{c}\text { Coefficient } \\
(\beta)\end{array}$ & $\begin{array}{c}\text { Standard } \\
\text { Error }\end{array}$ & p-value \\
\hline $\mathrm{B}_{0}$ & 14.18 & 0.69 & \\
\hline $\mathrm{X}_{1}$ & 1.91 & 0.54 & 0.0096 \\
\hline $\mathrm{X}_{2}$ & 0.36 & 0.54 & 0.5234 \\
\hline $\mathrm{X}_{3}$ & 2.18 & 0.54 & 0.0050 \\
\hline $\mathrm{X}_{1}{ }^{2}$ & -1.92 & 0.75 & 0.0368 \\
\hline $\mathrm{X}_{2}{ }^{2}$ & -0.12 & 0.75 & 0.8737 \\
\hline $\mathrm{X}_{3}{ }^{2}$ & -1.27 & 0.75 & 0.1324 \\
\hline $\mathrm{X}_{1} \mathrm{X}_{2}$ & -0.92 & 0.77 & 0.2679 \\
\hline $\mathrm{X}_{1} \mathrm{X}_{3}$ & 0.26 & 0.77 & 0.7458 \\
\hline $\mathrm{X}_{2} \mathrm{X}_{3}$ & 0.71 & 0.77 & 0.3850 \\
\hline $\mathrm{R}^{2}=0.8563$ & & & \\
\hline
\end{tabular}

Table 5. Coefficient of polynomial quadratic model of antioxidant activity

\begin{tabular}{|c|l|l|l|}
\hline $\begin{array}{c}\text { Antioxidant } \\
\text { Activity } \\
(\%)\end{array}$ & $\begin{array}{c}\text { Coefficient } \\
(\beta)\end{array}$ & $\begin{array}{c}\text { Standard } \\
\text { Error }\end{array}$ & $\mathrm{p}$-value \\
\hline $\mathrm{B}_{0}$ & 94.04 & 1.81 & \\
\hline $\mathrm{X}_{1}$ & 0.99 & 1.43 & 0.5111 \\
\hline $\mathrm{X}_{2}$ & 5.16 & 1.43 & 0.0088 \\
\hline $\mathrm{X}_{3}$ & 0.98 & 1.43 & 0.5172 \\
\hline $\mathrm{X}_{1}{ }^{2}$ & -2.32 & 1.98 & 0.2796 \\
\hline $\mathrm{X}_{2}{ }^{2}$ & -6.24 & 1.98 & 0.0161 \\
\hline $\mathrm{X}_{3}{ }^{2}$ & -7.44 & 1.98 & 0.0071 \\
\hline $\mathrm{X}_{1} \mathrm{X}_{2}$ & -2.02 & 2.03 & 0.3523 \\
\hline $\mathrm{X}_{1} \mathrm{X}_{3}$ & -3.73 & 2.03 & 0.1087 \\
\hline $\mathrm{X}_{2} \mathrm{X}_{3}$ & 1.36 & 2.03 & 0.5246 \\
\hline $\mathrm{R}^{2}=0.8692$ & & & \\
\hline
\end{tabular}

\subsection{Effect parameters on the extract yield}

Table 3 and 4 shows the response and interaction of extract yield of peanut skin extraction by supercritical carbon dioxide and co-solvent ethanol. 
$\mathrm{Y}=14.18+1.91 \mathrm{X}_{1}+0.36 \mathrm{X}_{2}+2.18 \mathrm{X}_{3}-1.92 \mathrm{X}_{1}^{2}-0.12$ $\mathrm{X}_{2}{ }^{3}-1.27 \mathrm{X}_{3}{ }^{3}-0.92 \mathrm{X}_{1} \mathrm{X}_{2}+0.26 \mathrm{X}_{1} \mathrm{X}_{2}+0.71 \mathrm{X}_{2} \mathrm{X}_{3}(3)$

Due to the coefficient of determination $\left(R^{2}\right) 0.853$ and p-value of model was 0.0278 , the second order polynomial model has been successfully fitted the experimental data of extract yield as shown on the Eq.3. From table 4, for the response extract indicated that pressure and rate of co-solvent ethanol were the most influence variables on the extraction process based on value of coefficient is higher than another variables.

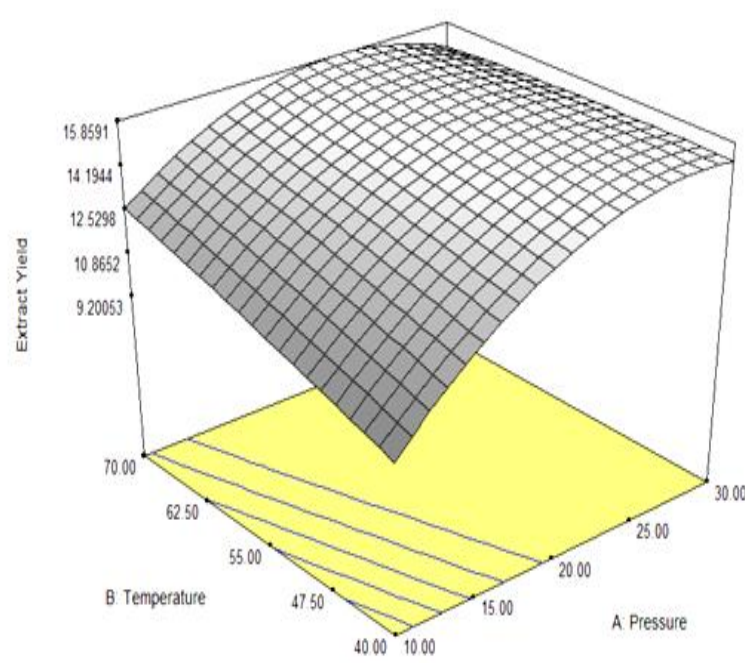

Fig.3. 3D response for the effect of pressure and temperature on the extract yield

Fig. 3 shows that extract yield increase with increasing of pressure $\left(\mathrm{X}_{1}\right)$ at constant lowest and highest temperature $\left(\mathrm{X}_{2}\right)$. This is because Increasing of solubility and density of $\mathrm{CO}_{2}$ to extract from the solute will be easily extract went out from the solute[8]. Increasing of pressure on the extraction process increases the density of carbon dioxide may affect of diffusivity of carbon dioxide to carry out of extract from solute[14]. This is similar funding with extraction of castor oil that increasing of pressure will increase the yield extracts[15]. It proofed that in the table $3 \mathrm{p}$-value of pressure $X_{1}$ is lower than p-value $(0.05>0.0096)$

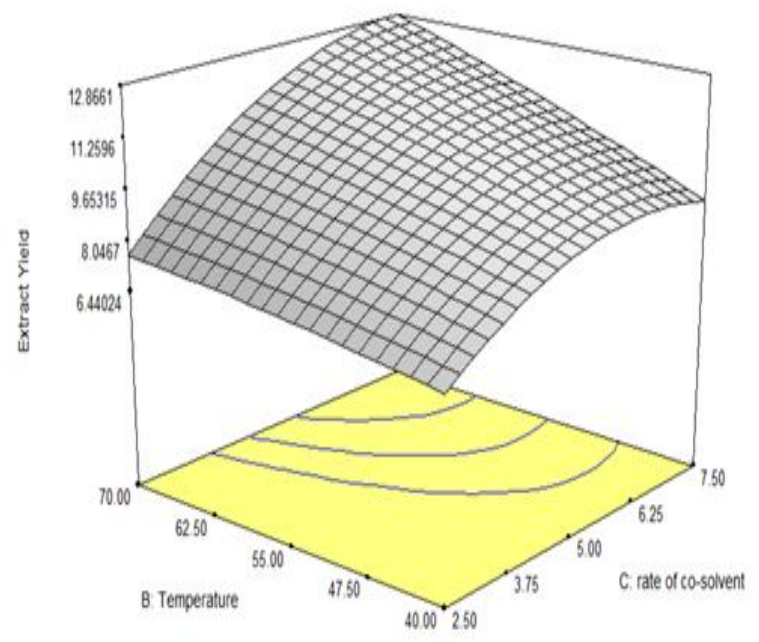

Fig.4. 3D response for the effect of temperature and rate of cosolvent on the extract yield

Increasing of the temperature at lowest pressure condition enhanced the yield extract of peanut skin, but effect of temperature have small effect on the extraction process due to coefficient of quadratic model and pvalue temperature is higher than $p$-value $(0.5234>0.05)$.

Fig. 4 and table 4 shows that the co-solvent ethanol was the main influence variable to obtain the maximum peanut skin extract. Ethanol as co-solvent is a polar solvent that can easily extract the polar compound from the peanut skin due to compositions of peanut skin extract are polar compounds such as catechin, epicatechin, procyanidin and anthocyanidin. The ethanol as co-solvent had a smaller value of significant than pressure $(0.005<0.0096)$.

The pressure $22.05 \mathrm{MPa}$, temperature $62.76{ }^{\circ} \mathrm{C}$ and $6.03 \%$ rate of co-solvent ethanol are optimum condition to obtain maximum extract yield $(15.4043 \%)$. The calculated of coefficient of determination $\left(\mathrm{R}^{2}\right)$ of the optimization of extraction with response yield extract was significance because the value is above 0.8 . Futhermore, p-value of model on the ANOVA was lower than 0.05. Quadratic model has been successful giving the optimum pressure, temperature and rate of co-solvent ethanol in range of adjustable.

\subsection{Effect parameters on the Antioxidant Activity}

Table 2 and 5 shows the response of antioxidant activity and interaction of parameters. The coefficient of regression model for extract yield was similar with extract yield model. Second order polynomial was successful to interpret the experimental data as shown in table 3 and can be written on Eq. 4

$\mathrm{Y}=94.04+0.99 \mathrm{X}_{1}+5.16 \mathrm{X}_{2}+0.98 \mathrm{X}_{3}-2.32 \mathrm{X}_{1}^{2}-6.24$
$\mathrm{X}_{2}{ }^{3}-7.44 \mathrm{X}_{3}^{2}-2.02 \mathrm{X}_{1} \mathrm{X}_{2}-3.73 \mathrm{X}_{1} \mathrm{X}_{2}+1.36 \mathrm{X}_{2} \mathrm{X}_{3}(4)$

Quadratic model has been successfully described and fitted the experimental data of antioxidant activity due to satisfactory coefficient $\left(\mathrm{R}^{2}\right)$ of response was high $(0.8692)$ and $p$-value model $(0.02079)$. Table 2 and 5 
shows temperature were the most influence on the extraction process because it had big values of coefficient compared with others. It is proofed that in the table $5 \mathrm{p}$-value of pressure $\mathrm{X}_{1}$ is lower than $\mathrm{p}$-value $(0.05$ $>0.008)$.. Quadratic rate-of co-solvent ethanol $\left(\mathrm{X}_{3}^{2}\right)$ was most influence in the extraction process due to $\mathrm{p}$-value and coefficient on the second order polynomial that is the highest value on the equation model.

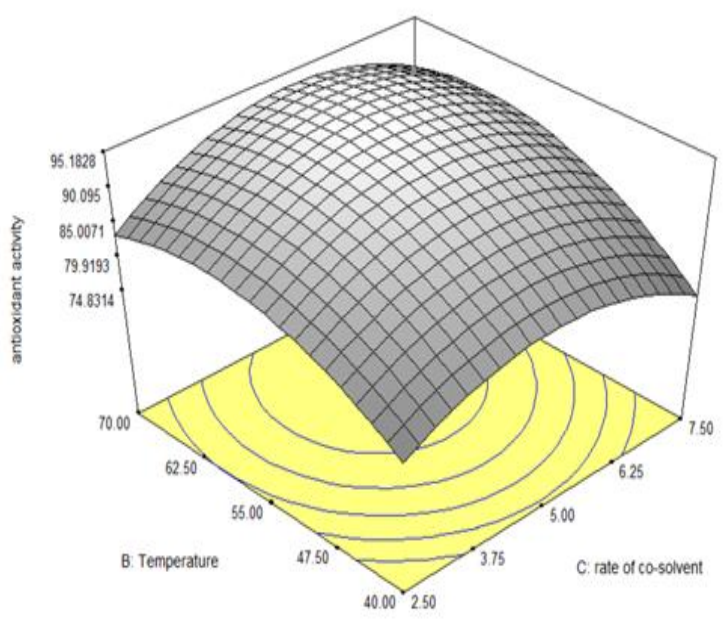

Fig.5. 3D response for the effect of temperature and rate of cosolvent ethanol on the antioxidant activity

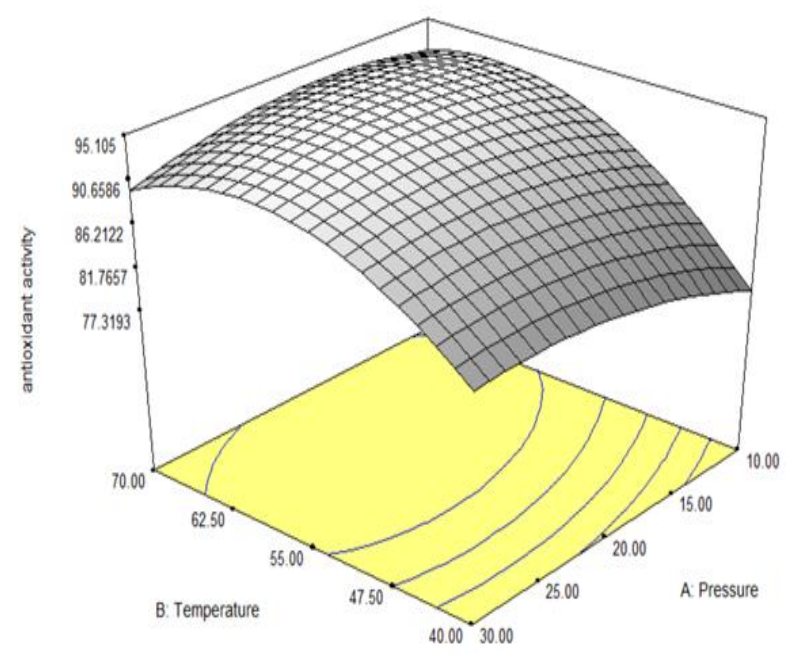

Fig. 6. 3D response for the effect of temperature and pressure on antioxidant activity

Fig 6 shows that increasing rate of co-solvent $X_{3}$ at lowest and highest temperature $\left(\mathrm{X}_{2}\right)$ reveals the peak optimum condition in the middle of range variables. Increasing of rate of co-solvent will enhance the polarity of solvent from nonpolar that without co-solvent to polar after added ethanol as co-solvent[16,17]. Furthermore, most of bioactive compound inside of peanut skin extract is polar compounds automatically will enhance the antioxidant activity [2].

From Fig 7, 3D response shows that in the effect of temperature, the model has already success to optimize the condition that optimal temperature was revealed. At the highest temperature condition, temperature will degrade the bioactive compound inside of extract, but in the lowest temperature condition, effect of the solute vapour is not dominant that solvent is difficult to carried out the extract and its bioactive compound from solute. Effect of pressure is not dominant in this extraction process to enhance the antioxidant of extract because increasing of pressure will not degrade the bioactive compound $[15,18]$. It was proofed that $p$-value on the coefficient of model was higher than 0.05. Furthermore, effect of vapour solute was revealed on this studies because increasing of temperature will increase the antioxidant activity $[19,17,5]$. There are more bioactive compound was successfully extracted from solute due to increasing of temperature. This is similar funding with extraction of jack fruit that increasing of temperature will increasing the antioxidant activity and yield of extract[20].

\subsection{Comparison antioxidant activity between supercritical carbon dioxide with co- solvent ethanol and soxhlet extraction}

In this study, extract of supercritical carbon dioxide with co-solvent ethanol gives the highest antioxidant activity compared with soxhlet extraction with various solvents (ethanol, water and n-hexane).

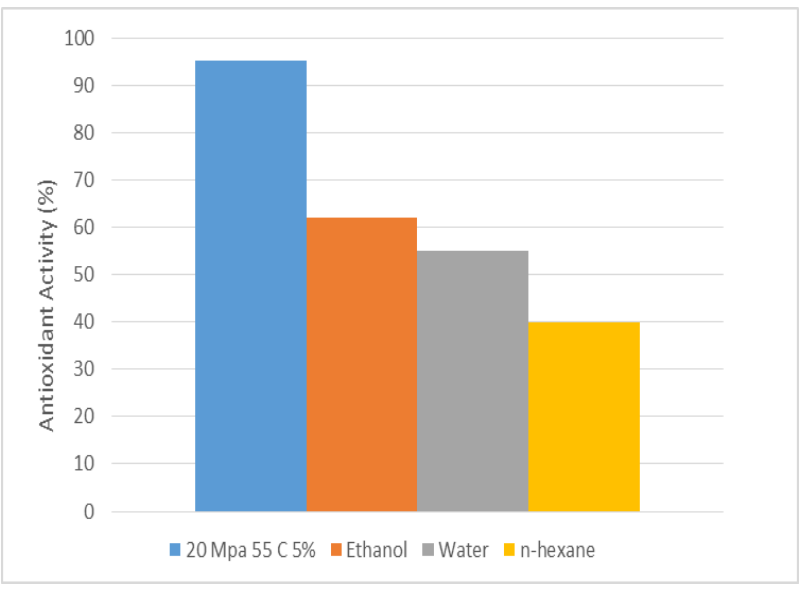

Fig.7. Comparison antioxidant activity between $\mathrm{SC}-\mathrm{CO}_{2}$ and soxhlet extraction with various solvents

Antioxidant activity of soxhlet extraction was lower than supercritical fluid extraction due to temperature of extraction process. Soxhlet extraction uses the high temperature to extract the solute that will degrade the bioactive compound of extract[21]. Antioxidant of extract with n-hexane as solvent is the lowest antioxidant activity indicated that most of compound inside of peanut skin is polar compound because n-hexane is non polar that is difficult to extract polar compound inside of peanut skin such as catechin, procyanidin, anthocyanidin and epicatechin [22],[2],[3].

\section{Conclusion}

The second order polynomial as quadratic model was chosen to optimize the supercritical carbon dioxide extraction with co-solvent ethanol with response 
optimum yield extract of peanut skin and antioxidant activity due to $\mathrm{p}$-value of model $(\mathrm{p}<0.05)$. The optimum yield peanut skin extract and antioxidant activity was $15.40 \%$ and $94.04 \%$ with conditions at $62.76{ }^{\circ} \mathrm{C}, 22.05$ $\mathrm{MPa}$ and $6.03 \%$ rate of co-solvent. Furthermore, the second order polynomial was successful to optimize the effect condition in the range variables adjusted and gave the maximum extract yield and antioxidant obtained. The supercritical carbon dioxide with co-solvent ethanol gave the higher antioxidant activity compared with soxhlet extraction due to temperature of extraction process. High temperature will degrade the bioactive compound and antioxidant activity of extract [23,24].

The authors acknowledge the Centre of Lipid Engineering and Applied Research (CLEAR) and the financial support from Universiti Teknologi Malaysia for professional development research university grant (QJ130000.2509.14H23) and (R.J130000.7909.4F766).

\section{References}

1. V. H. Hoang, P. Apoštolová, J. Dostálová, F. Pudil, and J. Pokorný, Czech J. Food Sci., 26, no. 6, 447457 (2008)

2. J. Yu, M. Ahmedna, and I. Goktepe, Food Chem., 90, no. 1-2, 199-206 (2005)

3. V. Nepote, N. R. Grosso, and C. a. Guzman, Grasas y Aceites, 53, no. 4, 391-395 (2002)

4. N. H. Arsad, M. Azizi, C. Yunus, M. Abbas, and A. Zaini, 12, no. 4, 741-751 (2016)

5. N. Lee, N. Sharif, A. Ahmad, and A. Khatoon, 17, no. 10, pp. 46-52 (2013)

6. A. N. Mustapa, Z. A. Manan, C. Y. Mohd Azizi, N. A. Nik Norulaini, and A. K. M. Omar, J. Food Eng., 95, no. 4, 606-616 (2009)

7. A. N. Mustapa, Z. A. Manan, C. Y. Mohd Azizi, W. B. Setianto, and A. K. Mohd Omar, Food Chem., 125, no. 1, 262-267 (2011)

8. M. C. Yunus and M. Hasan, J. ..., 60, 21-25, (2013).

9. C. Yi, J. Shi, S. J. Xue, Y. Jiang, and D. Li, Food Chem., vol. 113, no. 4, 1088-1094 (2009)

10. A. H. A. Aziz, M. A. C. Yunus, N. H. Arsad, N. Y. Lee, Z. Idham, and A. Q. A. Razak, IOP Conf. Ser. Mater. Sci. Eng., 162, no. 1, 12031 (2016)

11. L. S. Kassama, J. Shi, and G. S. Mittal, Sep. Purif. Technol., 60, no. 3, 278-284 (2008)

12. M. S. Md Sarip, Y. Yamashita, N. A. Morad, M. A. Che Yunus, and M. K. Abdul Aziz, J. Chem. Eng. Japan, 49, no. 7, 614-621 (2016)

13. C. S. G. Kitzberger, A. Smânia, R. C. Pedrosa, and S. R. S. Ferreira, J. Food Eng., 80, no. 2, 631-638 (2007)

14. H. P. Cornelio-Santiago, C. B. Gonçalves, N. A. de Oliveira, and A. L. de Oliveira, J. Supercrit. Fluids, 128, pp. 386-394 (2017)

15. J. M. Danlami, M. A. A. Zaini, A. Arsad, and M. A. C. Yunus, Ind. Crops Prod., 76, 34-40 (2015)
16. H. D. Belayneh, R. L. Wehling, A. K. Reddy, E. B. Cahoon, and O. N. Ciftci, JAOCS, J. Am. Oil Chem. Soc., 94, no. 6, 855-865 (2017)

17. S. C. S. Corzzini, H. D. F. Q. Barros, R. Grimaldi, and F. A. Cabral, J. Food Eng., 194, 40-45 (2017).

18. T. Sato, F. Fukuda, K. ichi Nihei, and N. Itoh, J. Supercrit. Fluids, 130, 23-29 (2017)

19. J. M. Danlami, M. A. A. Zaini, A. Arsad, and M. A. C. Yunus, J. Taiwan Inst. Chem. Eng., 53, 32-39 (2015)

20. M. A. C. Yunus, N. H. Arsad, S. Zhari, Z. Idham, S. H. Setapar, and A. N. Mustaph, J. Teknol. Sciences Eng., 60, 45-50 (2013)

21. M. C. Yunus and M. Hasan, J. ..., 60, 21-25, (2013)

22. T. S. Ballard, P. Mallikarjunan, K. Zhou, and S. F. O'keefe, J. Agric. Food Chem.,. 57, no. 8, 3064 3072 (2009)

23. L. P. Cunico, M. C. Acosta, and C. Turner, J. Supercrit. Fluids, (2017)

24. P. Khuwijitjaru, J. Plernjit, B. Suaylam, S. Samuhaseneetoo, R. Pongsawatmanit, and S. Adachi, Can. J. Chem. Eng., 92, no. 5, 810-815 (2014) 